\title{
Pulmonary embolism four days after interruption of therapy with rivaroxaban
}

\author{
Gabor Göndör'; Claudia Stöllberger ${ }^{1}$ \\ ${ }^{1}$ Krankenanstalt Rudolfstiftung, Wien, Austria
}

\begin{abstract}
Keywords
Non-vitamin K-antagonist, oral anticoagulants, rivaroxaban rebound phenomenon, atrial fibrillation, pulmonary embolism
\end{abstract}

\section{Summary}

Thrombosis after cessation of anticoagulation, also named rebound thrombosis, is a matter of concern and controversy. There are only few published data about occurrence of rebound thrombosis associated with non-vitamin K-antagonist oral anticoagulant drugs (NOACs). We report on a 58-year-old male with paroxysmal atrial fibrillation (AF) with a $\mathrm{CHA}_{2} \mathrm{DS}_{2}$ VASC score of 4 who developed central pulmonary embolism four days after interruption of rivaroxaban because of parotid surgery. He had received $40 \mathrm{mg}$ enoxaparin/d. The parotid gland was partially resected within 6 hours without blood loss. Pulmonary embolism and AF occurred on the first postoperative day. He recovered with low-molecular-weight heparin in therapeutic dosages and amiodarone and was discharged with phenprocoumon.

Korrespondenzadresse

Univ. Prof. Dr. Claudia Stöllberger

Steingasse 31/18

A-1030 Wien, Österreich

Tel.: 00436764031187

Fax: +431711652209

Email: claudia.stoellberger@chello.at
The relevance of a rivaroxaban rebound phenomenon, manifesting as arterial embolism, stroke or venous thromboembolism should be clarified. It should be assessed if rebound-phenomena also exist for the NOACs dabigatran, apixaban and edoxaban. Thus, the randomized trials and registries investigating patients with $\mathrm{AF}$ or venous thromboembolism should be re-analysed and, based on these data, recommendations should be developed for situations in which NOAC-therapy has to be interrupted or ceased.

\section{Schlüsselwörter}

Nicht Vitamin K-Antagonisten, orale Antikoagulantien, Rivaroxaban, Rebound-Phänomen, Vorhofflimmern, Pulmonalembolie

\section{Zusammenfassung}

$\mathrm{Ob}$ es nach Beendigung einer Antikoagulationstherapie zu einer neuerlichen Thromboembolie, auch „Rebound" genannt, kommen kann, ist umstritten und es gibt nur wenige

Pulmonalembolie vier Tage nach Unterbrechung

der Therapie mit Rivaroxaban

Phlebologie 2018; 47: 210-214

Nachdruck aus und zu zitieren als:

Hämostaseologie 2017; 37: 302-306

https://doi.org/10.5482/HAM0-17-01-0005

received: January 23, 2017

accepted in revised form: August 10, 2017

epub ahead of print: August 24, 2017

Funding

No support for the work in the form of grants, equipment, drugs or any combination of these
Daten über dieses Phänomen nach einer Therapie mit nicht Vitamin K-Antagonisten oralen Antikoagulantien (NOAKs). Ein 58-jähriger Mann mit paroxysmalem Vorhofflimmern (AF) und einem $\mathrm{CHA}_{2} \mathrm{DS}_{2}$ VASC Score von 4 erlitt eine zentrale Pulmonalarterienembolie vier Tage nach Unterbrechung der Therapie mit Rivaroxaban wegen eines chirurgischen Eingriffs an der Parotis. Zum Zeitpunkt des Ereignisses stand er unter einer Therapie mit $40 \mathrm{mg}$ Enoxaparin/Tag. Die Parotis wurde in einer 6-stündigen Operation ohne relevanten Blutverlust partiell reseziert. Am ersten postoperativen Tag traten eine Pulmonalembolie und tachykardes AF auf. Er erholte sich unter einer Therapie mit niedermolekularem Heparin in therapeutischer Dosis und Amiodaron und wurde mit einer Therapie mit Phenprocoumon entlassen.

Die Relevanz eines "Rivaroxaban-ReboundPhänomens", das als arterielle Embolie, Schlaganfall oder venöse Thromboembolie auftreten kann, sollte genauer erforscht werden. Es sollte festgestellt werden, ob ähnliche Phänomene auch bei den NOAKs Dabigatran, Apixaban und Edoxaban auftreten. Randomisierte Studien und Register, die Patienten mit AF oder venöser Thromboembolie eingeschlossen haben, sollten unter diesem Gesichtspunkt ausgewertet werden. Es sollten Empfehlungen ausgearbeitet werden für die Antikoagulation in Situationen, in denen die Therapie mit NOAKs unterbrochen oder beendet wird.

\section{Introduction}

Rivaroxaban is a direct anti-Xa oral anticoagulant and belongs to the group of non-Vitamin K-antagonist oral anticoagulants (NO-
ACs), which are increasingly used in patients with atrial fibrillation for prevention of stroke or embolism, based on the results of a large randomized trial (1). Furthermore, rivaroxaban is also approved for the treatment of ve- nous thromboembolism based on the results of two randomized trials $(2,3)$.

In comparison to the traditionally used vitamin-K-antagonists, the NOACs do not require any routine monitoring. On the ot- 
her hand, in emergency situations it is more difficult to estimate their plasma concentration and there are no recommended specific antidotes so far.

Furthermore, rivaroxaban and other NOACs carry a black box warning regarding the risk of rebound thrombosis after discontinuation $(4,5)$.

\section{Case report}

A 58-year-old male patient was admitted to our department because of an acute pulmonary embolism. He had a history of paroxysmal atrial fibrillation since 3 years, currently under therapy with rivaroxaban $20 \mathrm{mg}$, arterial hypertension since many years, peripheral arterial disease stage IIb since 5 years, fatty liver disease, prostatic hyperplasia, cholecystectomy 5 years before, lateral parotidectomy of the left parotid gland 13 years before, substituted hypothyroidism since the thyroidectomy at the age of 41years and appendectomy at the age of 14 years. His $\mathrm{CHA}_{2} \mathrm{DS}_{2}$ VASc score was 4 and the HAS-BLED score was 2. He was scheduled to an elective parotidectomy because of cystadenolymphoma of the right parotid gland.

Originally, he took phenprocoumon since 3 years, but the oral anticoagulation was changed to rivaroxaban six weeks before the actual surgery by his general practitioner. The cause for the readjustment was a transient ischemic attack of the right medial cerebral artery with sensory abnormality of the left arm for 15 minutes. The International Normalized Ratio at the time of the TIA was 2.75.

Preoperatively, the Caprini DVT risk score (a risk stratification score for perioperative venous thromboembolism) was 4, which corresponds to high risk and, in case of inclusion of TIA, the score would add up to 9 (6). He stopped taking rivaroxaban four days before the surgery and received enoxaparin sodium $40 \mathrm{mg}$ once daily. Besides, he took amlodipine/valsartan/hydrochlorothiazide 5/160/25 mg once, bisoprolol $5 \mathrm{mg}$ twice and levothyroxine sodium $100 \mu \mathrm{g}$ once daily. The surgery took 6 hours and succeeded without any complication. The patient had no blood loss and he did not need any erythrocyte concentrates. The histological result showed a partial resection of the parotid gland with two benign cystadenolymphomas.

Postoperatively the patient complained of pain in the right popliteal fossa and 15 hours after the end of the surgery, he started to suffer from sudden onset of severe dyspnea why he was transferred to the medical department. At admission, the blood pressure was $140 / 85 \mathrm{mmHg}$, the heart rate $150 / \mathrm{min}$ and the $\mathrm{O}_{2}$-saturation $88 \%$. After supplemental oxygen therapy with $5 \mathrm{l} / \mathrm{min}$, the oxygen saturation increased to $92 \%$. The D-dimer was $7.60 \mathrm{mg} / \mathrm{l}$ ( Table 1). The electrocardiogram showed tachycardious atrial fibrillation.

The CT-angiography of the pulmonary arteries showed a central pulmonary embolism on both sides of the lung reaching into the segmental arteries ( Figure 1).

Tab. 1 Laboratory findings

\begin{tabular}{|c|c|c|c|c|c|}
\hline $\begin{array}{l}\text { Parameter } \\
\text { (normal range) }\end{array}$ & $\begin{array}{l}\text { Day } 1 \\
(16: 10)\end{array}$ & $\begin{array}{l}\text { Day } 3 \\
(11: 16)\end{array}$ & $\begin{array}{l}\text { Day } 6 \\
(9: 02) \\
\end{array}$ & $\begin{array}{l}\text { Day } 8 \\
(09: 04) \\
\end{array}$ & $\begin{array}{l}\text { Day } 9 \\
(9: 22)\end{array}$ \\
\hline PT \% (70-140) & 111 & 95 & NM & NM & 94 \\
\hline INR & 0,91 & 1,01 & NM & NM & 1,01 \\
\hline D-Dimer mg/l $(-0,50)$ & NM & 7.60 & NM & NM & NM \\
\hline Leukocytes G/l (4-9) & NM & 17,6 & 13,6 & 12,5 & NM \\
\hline Thrombocytes G/I (150-400) & NM & 221 & 277 & 345 & NM \\
\hline Haemoglobin g/dl (14-17) & NM & 13,5 & 13,9 & 14,3 & NM \\
\hline CRP mg/l (-5) & NM & 39,5 & 28 & 13,9 & NM \\
\hline Sodium mmol/l (136-145) & NM & 141 & 141 & NM & 140 \\
\hline Potassium mmol// $(3,4-4,5)$ & NM & 3,8 & 3,9 & NM & 4,5 \\
\hline Creatinin mg/dl $(0,70-1,20)$ & NM & 0,75 & 0,80 & NM & 0,82 \\
\hline CK U/I (-190) & NM & 2075 & 422 & NM & NM \\
\hline CK-MB U/I (-25) & NM & 66 & 12 & NM & NM \\
\hline Troponin T ng/l (-14) & NM & NM & 17 & NM & NM \\
\hline Haemoglobin $\mathrm{A}_{1 \mathrm{c}} \%$ (4-6) & NM & NM & 6,7 & NM & NM \\
\hline Folic acid ng/ml $(4,60-18,70)$ & NM & NM & 3,67 & NM & NM \\
\hline Vitamin D3 nmol/l (75-) & NM & NM & 10,34 & NM & NM \\
\hline PSA mcg/l $(-3,200)$ & NM & NM & NM & 7,270 & NM \\
\hline ALT U/I (10-50) & NM & NM & 42 & NM & NM \\
\hline GGT U/I (-60) & NM & NM & 43 & NM & NM \\
\hline ALP U/I (40-129) & NM & NM & 66 & NM & NM \\
\hline Bilirubin mg/dl $(-1,20)$ & NM & NM & 0,53 & NM & NM \\
\hline
\end{tabular}

ALP = alkaline phosphatase; $A L T$ = alanine-aminotransferase; $C K=$ creatine phosphokinase; CRP = C-reactive protein; GGT = gamma-glutamyl transferase; INR = international normalized ratio; NM $=$ not measured; $\mathrm{PSA}=$ prostate-specific antigene; $\mathrm{PT}=$ prothrombin time
Concomitantly, the veins of the pelvis and lower extremities were investigated by CT and did not show any thrombosis. A bedside-echocardiography showed a slightly reduced left ventricular systolic function, a normally sized right ventricle with normal function, no pericardial effusion and no thrombus. Tachycardious atrial fibrillation was converted into sinus rhythm after the application of amiodarone, potassium and magnesium. Thrombolysis was considered but refused because of the recent surgery. Thus, enoxaparin sodium $100 \mathrm{mg}$ was injected as a bolus and prescribed two times daily. An oral anticoagulation therapy with phenprocoumon was initiated after 7 days and the patient was discharged without any complaints after 12 days. 

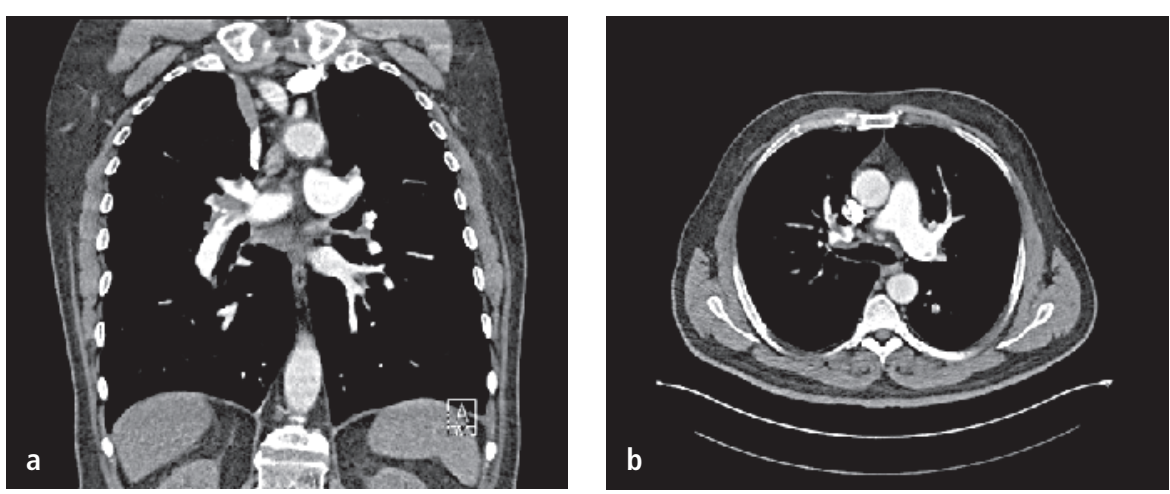

Fig. 1 Thrombus in the CT-angiography of the pulmonary arteries

\section{Discussion}

Rivaroxaban is a NOAC, which takes its effect by inhibiting the prothrombinasecomplex and the free factor Xa directly. The prothrombinase-complex is an enzymatic complex of the blood coagulation cascade consisting of the activated factors $\mathrm{X}$ and $\mathrm{V}$, calcium and phospholipids (7). The advantage of rivaroxaban compared to the vitamin-K-antagonists is that it does not require any routine monitoring. Based on randomized trials in patients with venous thromboembolism $(2,3)$, the guidelines of acute pulmonary embolism mention rivaroxaban $20 \mathrm{mg}$ once daily as an alternative to vitamin-K-antagonists if extended anticoagulation treatment is necessary as a class IIa, level B recommendation (8).

Rivaroxaban was also found to be noninferior to warfarin for the prevention of stroke and systemic embolism in patients with moderate- to high-risk nonvalvular atrial fibrillation and concerns about a potential rebound effect after cessation of rivaroxaban have been raised in association with the ROCKET AF (Rivaroxaban Once Daily Oral Direct Factor Xa Inhibition Compared with Vitamin K Antagonism for Prevention of Stroke and Embolism Trial in Atrial Fibrillation) study, a multicenter, randomized, double-blind trial with the participation of 14,264 patients (1). After the ROCKET AF study, an end of study (EOS) visit was performed and the participants were transitioned to open-label vitamin-K-antagonist-therapy. Between days 3 and 30, an excess of stroke and systemic embolic events were observed in participants assigned to rivaroxaban, and the me- dian time to reach a therapeutic INR value was 13 days in the rivaroxaban-group compared to 3 days in the warfarin-group (5, 9). Unfortunately, there are no data about venous thromboembolic events occurring after the ROCKET AF study since only stroke and arterial embolism were registered.

In our case, we considered three possible triggers that could have led to the thrombus formation and the subsequent pulmonary embolism.

First, the phenomenon of rebound thrombosis could have been a reason. Rivaroxaban carries a black box warning regarding the risk of thrombosis after discontinuation: „discontinuing rivaroxaban places patients at an increased risk of thrombotic events” and „an increased risk of stroke was observed following rivaroxaban discontinuation in clinical trials in atrial fibrillation patients" $(4,5)$. There are only limited data about the prevalence and clinical relevance of a rivaroxaban rebound phenomenon. Bakhit et al. reported a case with rebound thrombosis. Twenty-four hours after the cessation of rivaroxaban, an elective radiofrequency catheter ablation was performed but it had to be interrupted because a large septal thrombus in the left atrium was found (10).

The black box warning, however, exists for other oral anticoagulants as well. "Premature discontinuation of any oral anticoagulant in the absence of adequate alternative anticoagulation increases the risk of thrombotic events" (4). The direct oral anti Xa-inhibitors apixaban and edoxaban carry the same black box warning $(11,12)$. Regarding the direct oral thrombin-inhibitor dabigatran, the RE-MODEL trial suggested that dabigatran does not cause rebound thrombosis (13), other studies suggested the opposite (14). Thorne et al reported three arterial or venous thromboembolism cases within one month after cessation of dabigatran (15).

Data from a recently published non-industry-sponsored registry show that the NOACs rivaroxaban and dabigatran offer good protection against thromboembolic events in real-life patients with nonvalvular atrial fibrillation, but that interruptions of treatment represent a vulnerable period (16). In that registry, 866 patients with non-valvular atrial fibrillation with an average $\mathrm{CHA}_{2} \mathrm{DS}_{2}$-VASc-Score of 2.1, who were started on dabigatran or rivaroxaban, were analysed for thromboembolic events and survival. Patients who had temporary or permanent discontinuation of NOACs were compared to patients on continuous NOAC treatment. The incidence of thromboembolic events during treatment interruptions was more than 6-times higher than the "natural course" incidence predicted by the $\mathrm{CHA}_{2} \mathrm{DS}_{2}$-VASc-score. On the other hand, the incidence of thromboembolism was significantly lower in patients with uninterrupted NOAC treatment than the predicted incidence for untreated patients (16). Also in that registry, only arterial embolism and strokes, and no venous thromboembolic events, were counted.

The possibility of rebound thrombosis after cessation of therapy with vitamin $\mathrm{K}$-antagonists has been subject of discussion for a long time, e.g. by Genewein et al.in 1996 (17).

The pathophysiologic mechanism of a rivaroxaban rebound phenomenon is uncertain. Haynes et al., based on an in vitro study, suggested that the discontinuation of rivaroxaban leads to prothrombotic activity. The reason of this phenomenon may be that when rivaroxaban plasma concentrations decrease after cessation of therapy, there is an unmasking of thrombus-associated prothrombinase (18).

A second pathogenetic possibility for the thrombotic event in our case are the 6 hour-long surgery and the following hospitalization which are well known risk factors for thrombosis (19). However, the incidence of thrombosis and pulmonary embolism are not as common in patients after 
ear- nose- and throat-surgery than after other surgical specialties $(20,21)$. Obviously, enoxaparin 40mg was not sufficient to prevent venous thromboembolism in our patient. The relatively low dosage is debatable regarding the high risk in the Caprini score. Since the patient was transferred to the medical department only after experiencing the postoperative dyspnea, we were not involved in the decision-making regarding the perioperative bridging of his anticoagulation therapy.

Most of the recommendations regarding bridging of anticoagulant therapy during surgery are derived from patients treated with vitamin-K-antagonists. The American College of Chest Physicians (ACCP) international guidelines on anticoagulant perioperative bridging in patients with atrial fibrillation summarize the recommendation only for vitamin K-antagonists. After distinguishing between high risk and low risk for thromboembolism, a bridging therapy is recommended or not (22). New considerations to avoid the increased risk of thrombotic events after discontinuation suggest an uninterrupted approach in anticoagulation management during procedures (23). Kowalewski et al. performed a meta-analysis and came to the conclusion that in patients undergoing coronary angiography, the uninterrupted oral anticoagulation is safer than the discontinuation with bridging. Further studies, investigating other procedures are required to assess whether or not this approach would have been justifiable in our case. The BRIDGE trial was not included in the ACCP guidelines, and it reported that forgoing bridging anticoagulation was noninferior to perioperative bridging with low-molecular-weight heparin for the prevention of arterial thromboembolism and even decreased the risk of major bleeding (24). There was no significant difference between the bridging and non-bridging groups in the rates of deep vein thrombosis and pulmonary embolism either. However, this trial did not include any NOACs.

Spyropoulos et al. elaborated recommendations for bridging therapy both for vitamin K-antagonists and for direct oral anticoagulants depending on patient- and procedure-related risks of thromboembolism and bleeding, and the patient's renal function (25), which are slightly different from the
European Heart Rhythm Association (EH$\mathrm{RA}$ ) practical guide on the use of new oral anticoagulants in patients with non-valvular atrial fibrillation (26). If we apply these recommendations to our patient, the last dose of rivaroxaban should have been given three days before the surgery and accordingly to the EHRA, more than 48 hours preoperatively, assuming that we identify the procedure as a high bleeding risk surgery. In case of emergency procedures, Levy et al's publication is a helpful tool in the management and discontinuation of NOACs (27).

A third possibility for the thromboembolism could be heparin-induced thrombocytopenia, a complication of heparintherapy, associated with a prothrombotic state. Despite the definition "thrombocytopenia", this condition may rarely occur without a reduction of the number of platelets (28). Since the platelet count in our patient remained within the normal range at repeated measurements, heparin-induced thrombocytopenia (HIT) was considered as unlikely and no testing for HIT-antibodies was carried out.

It remains uncertain which of the three described mechanisms were responsible for the venous thromboembolism of our patient, and probably a coincidence of these different mechanisms may have played a role.

We conclude from this observation that there is an urgent need to clarify the rate of a rivaroxaban rebound phenomenon, manifesting as arterial embolism and stroke as well as venous thromboembolism. Furthermore, it has to be assessed if rebound phenomena also exist for other NOACs like dabigatran, apixaban and edoxaban. For that purpose, the data of the large randomized trials and registries investigating patients with atrial fibrillation or venous thromboembolism should be analysed. There is a need to develop recommendations for situations in which NOAC-therapy has to be interrupted or ceased. At present it remains uncertain if low-molecularweight heparin in therapeutic doses has to be administered for several days until the hypercoagulable state has resolved.

\section{Conflicts of interest}

The authors declare that they have no conflicts of interest.

\section{References}

1. Patel MR et al. Rivaroxaban versus warfarin in nonvalvular atrial fibrillation. N Engl J Med 2011; 365(10): 883-891.

2. Bauersachs $\mathrm{R}$ et al. Oral rivaroxaban for symptomatic venous thromboembolism. N Engl J Med 2010; 363(26): 2499-2510.

3. Buller HR et al. Oral rivaroxaban for the treatment of symptomatic pulmonary embolism. N Engl J Med 2012; 366(14): 1287-1297.

4. United States Food and Drug Administration. XARELTO (Rivaroxaban) tablets, for oral use. https://www.accessdata.fda.gov/drugsatfda_docs/ label/2017/202439s021lbl.pdf. Initial U.S. Approval: 2011.

5. Patel MR et al. Outcomes of discontinuing rivaroxaban compared with warfarin in patients with nonvalvular atrial fibrillation: analysis from the ROCKET AF trial (Rivaroxaban Once-Daily, Oral, Direct Factor Xa Inhibition Compared With Vitamin K Antagonism for Prevention of Stroke and Embolism Trial in Atrial Fibrillation). J Am Coll Cardiol 2013; 61(6): 651-658.

6. Caprini JA. Risk assessment as a guide to thrombosis prophylaxis. Curr Opin Pulm Med 2010; 16(5): 448-452.

7. Perzborn E et al. In vitro and in vivo studies of the novel antithrombotic agent BAY 59-7939 - an oral, direct Factor Xa inhibitor. J Thromb Haemost 2005; 3(3): 514-521.

8. Konstantinides SV et al. 2014 ESC Guidelines on the diagnosis and management of acute pulmonary embolism The Task Force for the Diagnosis and Management of Acute Pulmonary Embolism of the European Society of Cardiology (ESC) Endorsed by the European Respiratory Society (ERS). European Heart Journal 2014; 35: 3033-3080.

9. Mahaffey KW et al. End of study transition from study drug to open-label vitamin $\mathrm{K}$ antagonist therapy: the ROCKET AF experience. Circ Cardiovasc Qual Outcomes 2013; 6(4): 470-478.

10. Bakhit A et al. Rebound thrombosis within 24hours after interruption of therapy with rivaroxaban. Int J Cardiol 2016; 212: 235-236.

11. United States Food and Drug Administration. ELIQUIS (Apixaban) tablets, for oral use. https://www.accessdata.fda.gov/drugsatfda_docs/ label/2012/202155s000lbl.pdf. Initial U.S. Approval: 2012.

12. United States Food and Drug Administration. SAVAYSA (Edoxaban) tablets, for oral use. https://www.accessdata.fda.gov/drugsatfda_docs/ label/2015/206316lbl.pdf. Initial U.S. Approval: 2015.

13. Eriksson BI et al. Oral dabigatran etexilate vs. subcutaneous enoxaparin for the prevention of venous thromboembolism after total knee replacement: the RE-MODEL randomized trial. J Thromb Haemost 2007; 5(11): 2178-2185.

14. Hermans C, Claeys D. Review of the rebound phenomenon in new anticoagulant treatments. Curr Med Res Opin 2006; 22(3): 471-481.

15. Thorne KM, Dee S, Jayathissa S. Thrombotic events after discontinuing dabigatran: rebound or resumption? BMJ 2012; 345: e4469.

16. Vene $\mathrm{N}$ et al. Risk of Thromboembolic Events in Patients with Non-Valvular Atrial Fibrillation 
After Dabigatran or Rivaroxaban Discontinuation - Data from the Ljubljana Registry. PLoS One 2016; 11(6): e0156943.

17. Genewein $U$ et al. Rebound after cessation of oral anticoagulant therapy: the biochemical evidence. Br J Haematol 1996; 92(2): 479-485.

18. Haynes LM, Orfeo T, Mann KG. Rivaroxaban delivery and reversal at a venous flow rate. Arterioscler Thromb Vasc Biol 2012; 32(12): 2877-2883.

19. Caprini JA, Merli GJ, Bhatt DL. Update on Risk Factors for Venous Thromboembolism http://www.venousdisease.com/Publications/Up date\%20on\%20risk\%20factors-caprini.pdf. Am J Med 2005.

20. Nash R, Randhawa N, Saeed SR. Venous thromboembolism prophylaxis in ENT surgery: a survey of current practice. J Laryngol Otol 2015; 129(2): 164-167.

21. Chiesa Estomba $\mathrm{C}$ et al. The risk of venous thromboembolism in ENT and head \& neck surgery. Otolaryngol Pol 2015; 69(3): 31-36.

22. Guyatt GH et al. Executive summary: Antithrombotic Therapy and Prevention of Thrombosis, 9th ed: American College of Chest Physicians Evidence-Based Clinical Practice Guidelines. Chest 2012; 141(2 Suppl.): 7S-47S.

23. Kowalewski M et al. Meta-analysis of uninterrupted as compared to interrupted oral anticoagulation with or without bridging in patients undergoing coronary angiography with or without percutaneous coronary intervention. Int J Cardiol 2016 223: 186-194.
24. Douketis JD et al. Perioperative Bridging Anticoagulation in Patients with Atrial Fibrillation. N Engl J Med 2015; 373(9): 823-833.

25. Spyropoulos AC, Douketis JD. How I treat anticoagulated patients undergoing an elective procedure or surgery. Blood 2012; 120(15): 2954-2962.

26. Heidbuchel $\mathrm{H}$ et al. EHRA practical guide on the use of new oral anticoagulants in patients with non-valvular atrial fibrillation: executive summary. Eur Heart J 2013; 34(27): 2094-2106.

27. Levy JH. Discontinuation and Management of Direct-Acting Anticoagulants for Emergency Procedures. Am J Med 2016; 129(11S): S47-S53.

28. Alvarez GF, Bihari D, Collins D. Heparin-induced thrombosis with a normal platelet count. Crit Care Resusc 2007; 9(1): 51-53. 